\title{
Possible Complication Pneumothorax of in COVID-19
}

\author{
Bilge Aslan ${ }^{1, *}$, and Feray Aydm ${ }^{2}$ \\ ${ }^{1}$ Ankara Şehir Hastanesi, Anesthesia and Reanimation Clinic, Üniversiteler, Çankaya/Ankara, Turkey \\ ${ }^{2}$ Ankara Şehir Hastanesi, General Surgery Clinic, Üniversiteler, Çankaya/Ankara, Turkey
}

*Corresponding author: Bilge Aslan, Associate professor, Ankara Şehir Hastanesi, Anesthesia and Reanimation Clinic, Üniversiteler, Çankaya/Ankara, Turkey, Tel: 03125526000; E-mail: drbilgeaslan@hotmail.com

Received: 05 Jun, 2021 | Accepted: 16 Nov, 2021 | Published: 23 Nov, 2021

Citation: Aslan B, Aydm F (2021) Possible Complication Pneumothorax of in COVID-19. J Clin Case Stu 6(6): dx.doi.org/10.16966/24714925.241

Copyright: (C) 2021 Aslan B, et al. This is an open-access article distributed under the terms of the Creative Commons Attribution License, which permits unrestricted use, distribution, and reproduction in any medium, provided the original author and source are credited.

\begin{abstract}
Two male patients, 57 and 58 years old, were evaluated in our emergency department. The complaints of cough that had been continuing for 1 week was at the forefront in their histories. Diarrhea and fever accompanied. In both patients, the complaint of shortness of breath increased significantly in the last 6 hours. Although 20lt/min oxygen was given to hypoxemic patients, $\mathrm{SpO}_{2}$ values were in the range of $80 \%$ to $84 \%$. Despite oxygen supplementation, the current sinus tachycardia $(140 \mathrm{bpm})$ did not improve. In the thorax x-ray evaluations which were performed immediately, it was seen that both patients had pneumothorax covering the entire left hemithorax. The patients were connected to the underwater drainage system by inserting a chest tube. In clinical radiological follow-up, pneumothorax regressed and lung parenchyma was re-expanded in both cases. A contralateral pneumothorax occurred in the second patient. Conditions observed in these cases show that pneumothorax can be caused by Covid-19 and may be mortal. Pneumothorax should be kept in mind in the presence of severe dyspnea, hypoxia and tachycardia when suddenly added to the clinic. Both patients died in their second week of intensive care unit treatment.
\end{abstract}

Keywords: COVID-19; Pneumothorax; Mortality

\section{Case Presentations}

Two male patients, 57 and 58 years old, were evaluated in our emergency service. The complaint of cough that had been continuing for 1 week was at the forefront in his histories. Diarrhea and fever accompanied this picture. In both patients, the complaint of shortness of breath increased significantly in the last 6 hours. Although 20lt/ min oxygen was given to hypoxemic patients, $\mathrm{SpO}_{2}$ values were in the range of $80-84 \%$. Despite oxygen supplementation, the current sinus tachycardia (140bpm) did not improve. The arterial blood pressure in the patients was at the level of $100 / 60 \mathrm{mmHg}$. Partially, there was a decrease in cognitive functions with confusion. Although cooperation could be established, GKS was 14/15 from time to time. The patients had high fever (380 degrees and higher). Both patients had diabetes mellitus, arterial hypertension, and a history of smoking.

\section{Diagnostic tests}

Thorax posteroanterior roentgenography of the patients revealed large left-sided pneumothorax with a right shift in the mediastinum and radiological signs of tension (Figure 1). When the right lung was compressed, it showed severe signs of COVID-19, widespread irregular consolidative changes. The patient's complete blood count showed an increased white cell count with neutrophilia (first patient: $14.84 \times 10^{9} / \mathrm{L}$, second patient: $\left.7.87 \times 10^{9} / \mathrm{L}\right)($ first patient: $15.94 \times$ $10^{9} / \mathrm{L}$, second patient: $8.97 \times 10^{9} / \mathrm{L}$ ), lymphocyte count (first patient: $0.35 \times 10^{9} / \mathrm{L}$ second patient: $0.52 \times 10^{9} / \mathrm{L}$ ), hemoglobin (first patient:
$9.6 \mathrm{mg} / \mathrm{dL}$, second patient: $8.9 \mathrm{mg} / \mathrm{dL}$ ) and platelets (first patient: $278 \times 10^{9} / \mathrm{L}$, second patient: $144 \times 10^{9} / \mathrm{L}$ ); biochemical markers, an elevated C-reactive protein (first patient: $80.4 \mathrm{mg} / \mathrm{L}$, second patient: $180 \mathrm{mg} / \mathrm{L}$ ), IL-6 (first patient: $10.9 \mathrm{pg} / \mathrm{mL}$, second patient: $11.2 \mathrm{pg} /$ $\mathrm{mL}$ ), and alanine aminotransferase showed (first patient: 102IU/L, second patient: $98 \mathrm{IU} / \mathrm{L}$ ). Based on these findings, the presence of a secondary bacterial pneumonia was thought to be strongly possible. Repeat chest radiography was also performed, confirming the reexpansion of the lung with extensive bilateral consolidation (Figure 2). In thorax CT examinations performed in clinical follow-ups, the areas of consolidation as widespread patch were diagnosed as bullous compatible and associated with COVID-19 infection (Figure 3).

\section{Differential diagnosis}

During the pandemic period, patients should be considered as covid until otherwise clinically defined. In the differential diagnosis of dyspnea, other viral or bacterial pneumonias, Type-1 respiratory failure, lung parenchymal diseases, mitral valve stenosis, and heart failure should be considered. Unilateral listening findings are generally incompatible with covid infection [1,2]. While sudden deterioration in this patient's clinic may be a result of isolated SARS-CoV2 infection, rapid decompensation and unilateral examination findings here are atypical as the primary cause. An important differential diagnosis for the acute picture is Pulmonary Embolism (PE). Patients with PE present with hypoxia and tachycardia, and if left untreated, it can be mortal [3]. The literature shows well that COVID-19 can occur with 


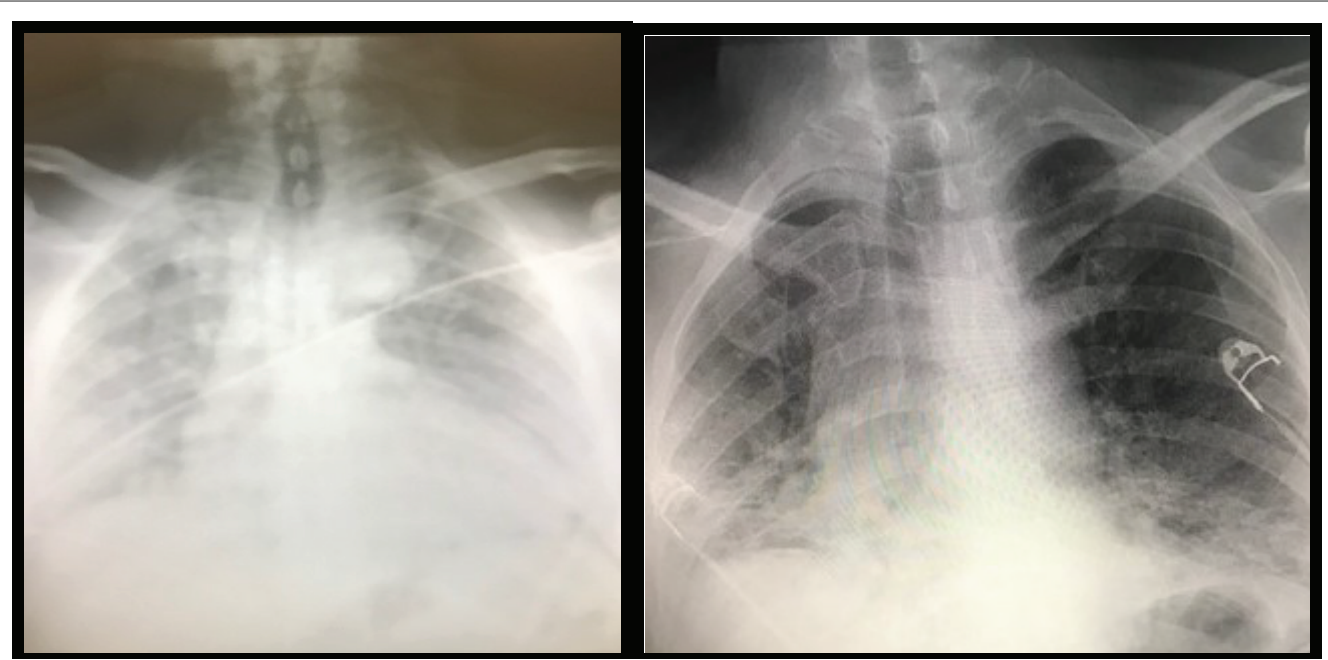

Figure 1: Portable chest radiograph demonstrating a left-sided tension pneumothorax, with mediastinal shift and consolidation throughout the right lung.

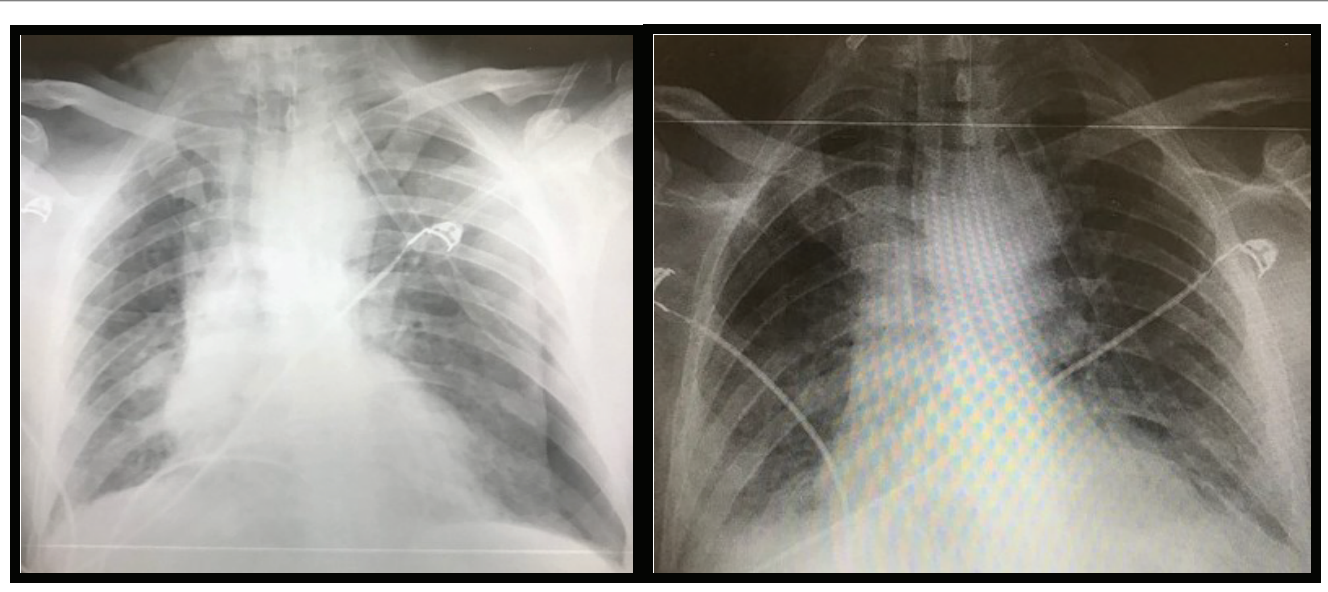

Figure 2: Portable chest radiograph demonstrating lung re-expansion and extensive bilateral consolidation in keeping with severe COVID-19.

hemoptysis (a symptom of acute PE), and patients who are not sick for a long time have a higher risk of developing venous thromboembolism. In the literature, $\mathrm{PE}$ is defined as part of the COVID-19 infection that causes acute worsening in patients [4].

\section{Treatment}

After thorax roentgenography, emergency decompensation of $14 \mathrm{G}$ cannula was applied to the second intercostal space at midclavicular speed. Subsequently, a $12 \mathrm{~F}$ chest tube was placed in the armpit. Underwater drainage was taken. Pulse steroid therapy was applied for 3 days $(2.5 \mathrm{~g})$ and cytokine filter for 3 days in both patients. The patients died on the $11^{\text {th }}$ and $17^{\text {th }}$ days of their intubation, respectively.

Chest tube therapy provided immediate improvement in respiratory and cardiovascular physiology with clinical and radiological evidence of lung remodeling (Figure 3). Within an hour, the patient's oxygen requirement, respiration and heart rate reached normal limits. Oxygen support was reduced to $4-6 \mathrm{~L} / \mathrm{min}$ via nasal cannula. However, the first of the patients was intubated on the $3^{\text {rd }}$ day and the second on the $12^{\text {th }}$ day due to the increase in respiratory distress. Transthoracic echocardiography performed at the bedside of the first patient revealed an image compatible with vegetation in the right ventricle. Gram positive cocci was observed in deep tracheal aspirates of the patients with C. albicans and E. coli, blood cultures of the patients, and $C$. paraphilosis in the urine cultures of the patients. Intravenous teicoplanin, colistin, tigecycline and fluconazole were given to our patients.

\section{Discussion}

These cases suggest that tension pneumothorax should be considered as a cause of acute worsening in patients with SARS$\mathrm{CoV} 2$ infection. Missing clues of pneumothorax may cause the preference of high positive pressure ventilation and worsening of the clinical status. Bedside ultrasound is gaining increasing acceptance in the management of COVID-19 and, if used previously, may have resulted in a rapid diagnosis of pneumothorax for each case [1-3]. It is important to acknowledge that we cannot be sure whether this pneumothorax is secondary to COVID-19 or whether the co-infection is entirely accidental. We do not know the presence of bullous lungs before covid, since our patients did not have lung imaging before. 


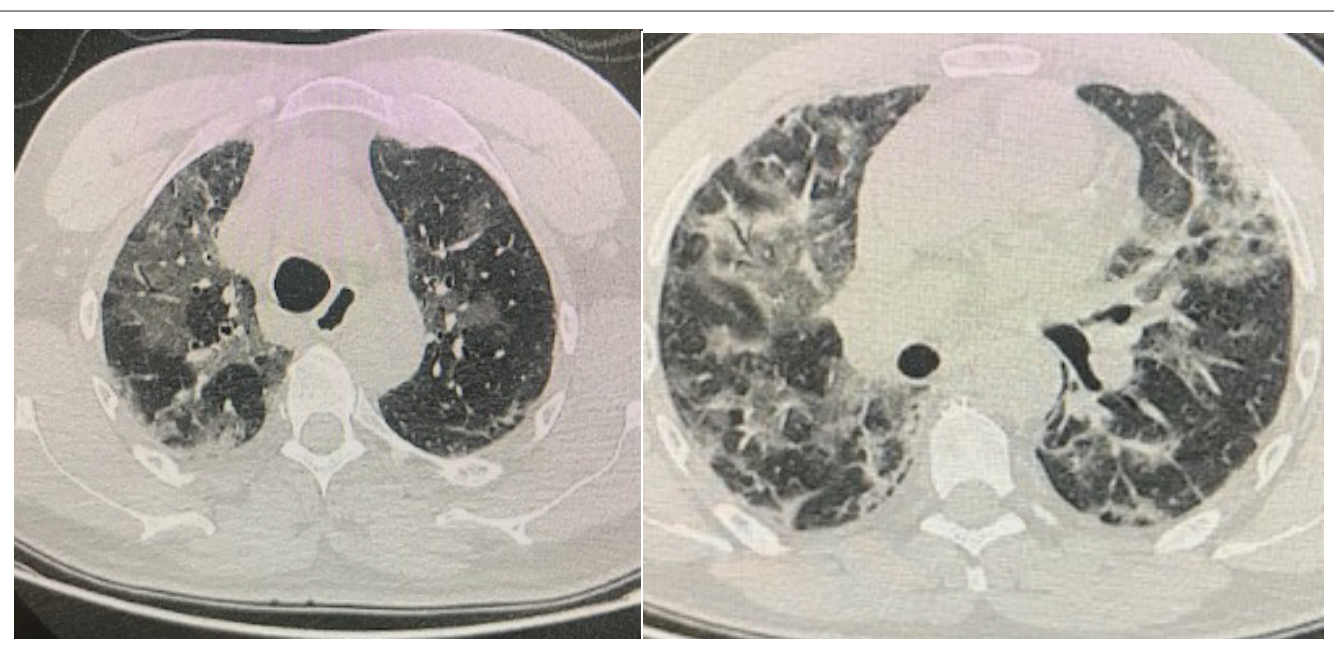

Figure 3: Thoracic CT demonstrating widespread areas of patchy consolidation, findings consistent with severe COVID-19 infection, with associated bullae.

No case of tension pneumothorax with concurrent COVID-19 infection has been published in the literature, and there is one case of spontaneous pneumomediastinum reported from China [4,5].

Many cases in the literature of possible relevance describe the presence of pneumatocoeles in patients with COVID-19, a pathological finding that may contribute to the possibility of developing secondary pneumothorax $[5,6]$. These cases further highlight the challenges faced by emergency department clinicians during the current pandemic. Until proven otherwise, local hospital guidelines recommend CPAP/PEEP within 10 minutes after presentation for all patients with suspected COVID-19 and $<94 \% \mathrm{SpO}_{2}$ (i.e., $60 \% \mathrm{FiO}_{2}$ ) in high flow oxygen for patients who present with respiratory failure often presumed to have COVID-19. If we had followed current guidelines and initiated CPAP/ PEEP in these patients, it would likely result in significant worsening and possible cardiac arrest. Critically, it is extremely important to avoid taking a purely algorithmic approach to patients. Many clinicians can now be anxious to oscultate patient's lungs regularly due to concerns about exposure to SARS-CoV2 or, in some cases, the lack of disposable stethoscopes. Accepted COVID-19 patients treated with non-invasive and invasive forms of ventilation require close monitoring as the risk of ventilator-associated pneumothorax may be increased.

\section{Conclusion}

While protocols continue to be the key to managing serious patients, they cannot replace detailed history taking and clinical examination. Pneumonia Severity Index and other scoring systems have prognostic value $[7,8]$. The severity scores of our patients in the intensive care unit we mentioned in this publication were 3 . In our opinion, subcutaneous emphysema and pneumothorax should be added to this risk scoring for COVID-19 patients.

\section{References}

1. Jalaber C, Lapotre $T$, Morcet-Delattre $T$, Ribet $F$, Jouneau $S$, et al. (2020) Chest CT in COVID-19 pneumonia: A review of current knowledge. Diagn Interv Imaging 101: 431-437.

2. Peng QY, Wang XT, Zhang LN, Chinese Critical Care Ultrasound Study Group (2020) Findings of lung ultrasonography of novel corona virus pneumonia during the 2019-2020 epidemic. Intensive Care Med 46: 849-850.

3. Riedel M (2001) Acute pulmonary embolism 1: Pathophysiology, clinical presentation, and diagnosis. Heart 85: 229-240.

4. Danzi GB, Loffi M, Galeazzi G, Gherbesi E (2020) Acute pulmonary embolism and COVID-19 pneumonia: a random association? Eur Heart J 41: 1858.

5. Zhou C, Gao C, Xie Y, Xu M (2020) COVID-19 with spontaneous pneumomediastinum. Lancet Infect Dis 20: 510.

6. Shi H, Han X, Jiang N, Cao Y, Alwalid O, et al. (2020) Radiological findings from 81 patients with COVID-19 pneumonia in Wuhan, China: a descriptive study. Lancet Infect Dis 20: 425-434.

7. Gorbalenya AE, Baker SC, Baric RS, de Groot RJ, Drosten C, et al. (2020) Severe acute respiratory syndrome - related coronavirus: the species and its viruses - a statement of the Coronavirus Study Group. BioRxiv.

8. Zhou F, Yu T, Du R, Fan G, Liu Y, et al. (2020) Clinical course and risk factors for mortality of adult inpatients with COVID-19 in Wuhan, China: a retrospective cohort study. Lancet 395: 1054-1062. 